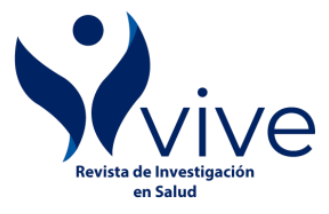

VIVE. Revista de Investigación en Salud https://doi.org/10.33996/revistavive.v4i11.98

Volumen 4 | No. 11 | Mayo - agosto 2021 http://revistavive.org

ISSN: $2664-3243$

ISSN-L: $2664-3243$

pp. $345-357$

\title{
Susceptibilidad de cepas de $S$. aureus aisladas en superficies hospitalarias
}

\author{
Susceptibility of S. aureus strains isolated on hospital surfaces
}

Suscetibilidade de cepas de S. aureus isoladas em superfícies hospitalares

\author{
Marcia Lucia Sanmartín Orbe \\ marcia151@live.com \\ https://orcid.org/0000-0003-4674-8471
}

\author{
Carlos Fernando Andrande Tacuri \\ candradet@ucacue.edu.ec \\ https://orcid.org/0000-0003-3983-1314
}

\author{
Paola Patricia Orellana Bravo \\ porellana@ucacue.edu.ec \\ https://orcid.org/0000-0001-6276-0521
}

\section{Programa de Maestría en Diagnóstico de Laboratorio Clínico y Molecular, Universidad Católica de Cuenca, Cuenca-Ecuador}

Recibido 26 de marzo 2021 | Arbitrado y aceptado 14 deabril 2021 | Publicado en 4 de mayo 2021

\begin{abstract}
RESUMEN
Las infecciones nosocomiales por Staphylococcus aureus tiene una alta prevalencia, debido a que esta bacteria forma parte de la microbiota de la piel del personal de salud y pacientes. Este microorganismo debido a su ubicuidad está presente en superficies y fómites, convirtiéndose en vectores para la trasmisión de infecciones. Objetivo. Describir el perfil de susceptibilidad antibiótica de cepas de $S$. aureus aisladas en superficies de un hospital de la ciudad de Cuenca. Materiales y métodos. Se realizó un estudio con enfoque cuantitativo, de corte transversal, descriptivo. Se recolectaron 200 muestras de diferentes superficies de áreas hospitalarias, en las que se identificó $S$. aureus mediante la amplificación de genes nucA Y femB. La susceptibilidad fenotípica a los antibióticos se determinó por el método de Kirby Bauer. Resultados. Se identificaron 6 cepas de $S$. aureus distribuidas de la siguiente manera: 2 cepas en el área de emergencia (33.33\%) y 1 cepa (16.66\%) en cada una de las áreas de: vestidores, rayos X, ecografía y odontología. La totalidad de estos aislados resultaron resistentes a: penicilina, oxacilina y amoxacilina; sensibles a trimetoprim sulfametoxazol, rifampicina, tetraciclina, cloranfenicol, vancomicina y linezolid. En el caso de la gentamicina se encontró: 3 cepas sensibles, 1 con sensibilidad intermedia y 2 resistentes. Conclusión. Se aislaron 6 cepas de $S$. aurues, en las cuales se pudo medir la susceptibilidad a diferentes antibióticos.
\end{abstract}

Palabras clave: $S$. aureus; antibióticos; superficies hospitalarias
MS: Bioquímica Farmacéutica. Experiencia en el área de laboratorio clínico. Cursando la maestría en Diagnóstico clínico y molecular Universidad Católica de Cuenca, Ecuador.

CA: Doctor en Bioquímica y Farmacia. Especialista en Docencia Universitaria. Magister en Nutrición Infantil. Magister en Nutrición y Dietética. Docente universitario. Director de carrera de Bioquímica y Farmacia. Universidad Católica de Cuenca, Ecuador.

PO: Magister En Biotecnología. DocenteInvestigadora de la carrera de Odontología. Custodia de los equipos del Laboratorio de
Genética y Biología Molecular del CIITT (Centro denética y Biología Molecular del CIITT (Centro Tecnología) de la Universidad Católica de Cuenca, Ecuador.

\begin{abstract}
Nasocomial infections by Staphylococcus aureus have a high prevalence, because this bacterium is part of skin microbiota of health personnel and patients. This microorganism for its ubiquity is present on surfaces and fomites becoming vectors for the transmission of infecions. Objective. Describe the antibiotic sisceptibility profile of $S$. aureus strains isolated from surfaces of hospital the city of Cuenca. Materials and methods. Is a quantitative cross sectional, descriptive, 200 samples were collected from different surfaces of hospital areas, in which S. aureus was identified through the amplification of nucA and femB genes. Phenotipic susceptibility to antibiotics was determined by the Kirby Bauer method. Results. 6 strains of $S$. aureus were identified, distributes as follows: 2 strains in the emergency area (33.33\%) and $1(16.66 \%)$ in each of the areas: dressing rooms X-rays, ultrasound and dentistry. All of these isolates were resistant to: penicillin, oxacillin, and amoxacillin; sensitive to trimethoprim sulfamethoxazole, rifampin, tetracycline vancomycin and linezolid. In the case of gentamicin, it was found: 3 sensitive strains, 1 with intermediate sensitivity and 2 resistant. Conclusion. Six strains of $S$. aureus were isolates, in which the susceptibility to different antibiotics could be measured.
\end{abstract}

Key words: $S$. aureus; antibiotics; hospital; surfaces 
MS: Bioquímica Farmacéutica. Experiencia en el área de laboratorio clínico. Cursando la maestría en Diagnóstico clínico y molec CA: Doctor en Bioquímica y Farmacia Especialista en Docencia Universitaria. Magiste en Nutrición Infantil. Magister en Nutrición y carrera de Biontémiversitario. Director y Católica de Cuenca, Ecuador.

PO: Magister En Biotecnología. DocenteCustodia de los equipos del Laboratorio de Genética y Biología Molecular del CIITT (Centro Genética y Biología Molecular del CIITT (Centro Tecnología) de la Universidad Católica de Cuenca, Ecuador.

\section{RESUMO}

As infecções nosocomiais por Staphylococcus aureus têm uma elevada prevalência, devido ao facto desta bactéria fazer parte da microbiota cutânea do pessoal de saúde e dos pacientes. Devido à sua ubiquidade, este microorganismo está presente nas superfícies e fomenta, tornando-se um vector de transmissão de infecções. Objectivo. Descrever o perfil de susceptibilidade aos antibióticos das estirpes de $S$. aureus isoladas das superfícies de um hospital na cidade de Cuenca. Materiais e métodos. Foi realizado um estudo quantitativo, transversal e descritivo. Duzentas amostras foram recolhidas em diferentes superfícies de áreas hospitalares, nas quais $S$. aureus foi identificado por amplificação dos genes nucA e femB. A susceptibilidade fenotípica aos antibióticos foi determinada pelo método de Kirby Bauer. Resultados. Foram identificadas seis estirpes de $S$. aureus, distribuídas da seguinte forma: duas estirpes na área de emergência $(33,33 \%)$ e uma estirpe $(16,66 \%)$ em cada uma das seguintes áreas: camarins, raio-x, ultra-som e odontologia. Todos estes isolados eram resistentes à penicilina, oxacilina e amoxacilina; sensíveis ao trimetoprim sulfametoxazol, rifampicina, tetraciclina, cloranfenicol, vancomicina e linezolida. No caso da gentamicina encontramos: 3 estirpes sensíveis, 1 com sensibilidade intermédia e 2 resistentes. Conclusão. 6 estirpes de $S$. aurues foram isoladas, nas quais a susceptibilidade a diferentes antibióticos podia ser medida.

Palavras-chave: S. aureus; antibióticos; superfícies hospitalares

\section{INTRODUCCIÓN}

$\mathrm{E}$ l género Staphylococcus agrupa una variedad de especies bacterianas, entre las cuales destaca Staphylococcus aureus (S. aureus), cuya importancia radica en su perfil de virulencia y resistencia antibiótica $(1,2)$. Frecuentemente se lo encuentra en una gran variedad de superficies, y a pesar de formar parte de la microbiota en fosas nasales, mucosa orofaríngea y piel de seres humanos (3), es el principal patógeno aislado en infecciones de tejidos blandos, cutáneas, osteoarticulares, endovasculares, implantes, cardiacos, etc (4).

$S$. aureus se encuentra dentro del grupo de bacterias que forman parte del acrónimo "ESKAPE", que son microorganismos que tienen la facilidad de inhibir los mecanismos de acción de los antimicrobianos, esta habilidad de crear resistencia a múltiples antimicrobianos lo convierte en un importante problema de salud publica (5). La diversidad patogénica de esta bacteria está relacionada con su capacidad de portar genes de resistencia, entre los que desatacan mecA, mecC, blaZ, vanA, etc (6).

La era antibiótica comenzó a con el descubrimiento de las propiedades antimicrobianas de la penicilina por Alexander Fleming. En 1941 se extiende su uso como antibiótico de elección contra infecciones por diferentes tipos de microorganismos (7). Sin embargo, en 1944 ya se reportaron los primeros casos de $S$. aureus productoras de $\beta$-lactamasa con actividad penicilinasa codificada por el gen blaz (8).

A raíz de esta problemática surgieron nuevos antimicrobianos, como la meticilina que en 1959 se convirtió en la primera opción terapéutica contra las cepas resistentes a penicilina. Lamentablemente en 1961 se describieron los primeros casos de S. aureus resistente a la meticilina (SARM) (9), generado por el gen mecA que codifica para PBP2a (proteína fijadora de penicilina 2 modificada) (10).

En este contexto, la vancomicina es el antibiótico de primera línea para tratar infecciones producidas por SARM (11), y no 
fue hasta 1990 cuando se reportó por vez primera $S$. aureus con resistencia intermedia a vancomicina (VISA, por sus siglas en inglés). Este hecho representó una alarma para los sistemas de salud, ya que esta resistencia se relaciona con la transferencia horizontal de los genes vanA, vanB y vanC $(12,13)$. Los nuevos fármacos para el tratamiento de cepas de $S$. aureus multirresistentes con linezolid, tigeciclina y daptomicina $(14,15)$.

Esta bacteria ubicua se ha logrado aislar de una gran diversidad de superficies como piel y mucosas del personal de salud, salas de cuidados intensivos, quirófanos, salas de emergencia, etc. Una de las características de mayor importancia de $S$. aureus es su capacidad de permanecer viable en superficies inertes desde algunas semanas hasta varios meses, convirtiéndose en el principal microorganismo nosocomial $(16,17)$.

Las infecciones relacionadas con la asistencia sanitaria son las que se adquieren durante la estancia hospitalaria, las cuales se contraen 48 horas después de ser hospitalizado, y pueden ser causada por la flora intrahospitalaria, o por la microbiota del personal de salud o del mismo paciente $(18,19)$, lo cual representa una complicación en las personas hospitalizadas pasando a ser el principal problema de mobimortalidad (20).

En un artículo realizado en un hospital de Cali, los investigadores registraron un 12.2\% de $S$. aureus en ambientes hospitalarios (22).

Por otra parte, una investigación realizada en quirófanos y salas de cuidados intensivos de un hospital de Cuenca- Ecuador, reportó una frecuencia del $6 \%$ de $S$. aureus y el $66.6 \%$ de resistencia a penicilina y meticilina en las cepas aisladas (23).

En un hospital de Brasil la posibilidad de MRSA antes de la limpieza fue $19 \%$ en 32 barandas de camas, luego de la desinfección de estas superficies el crecimiento de MRSA fue de $12.5 \%$, lo cual evidencia la capacidad de esta bacteria a sobrevivir en diferentes superficies (21).

En investigaciones previas se evidencia la presencia de $S$. aureus en superficies hospitalarias y su resistencia a diversos antibióticos. Esto podría generar complicaciones en pacientes hospitalizadas, alargando su estancia en la casa de salud y aumentado los costos invertidos por el sistema de salud. Además la presencia de $S$. aureus en entornos hospitalarios podría complicar la labor del personal de salud al presentarse una infección nosocomial por esta bacteria.

Esta investigación tiene como objetivo principal describir el perfil de susceptibilidad antibiótica de cepas de $S$. aureus aisladas en las superficies de las áreas de un hospital de la ciudad de Cuenca.

En este contexto resulta relevante conocer la presencia de esta bacteria y su susceptibilidad a diferentes antimicrobianos, en áreas hospitalarias. Estos resultados serán de gran ayuda para establecer medidas de prevención, como higiene de manos más frecuentes y optar por medidas de desinfección en las áreas hospitalarias, con el objetivo de prevenir que estas se conviertan en un reservorio de $S$. aureus y otros microorganismos patógenos.

\section{MATERIALES Y MÉTODOS}

$\mathrm{E}$ l estudio realizado fue de tipo no experimental, descriptivo ya que no se manipularon variables, el diseño de la investigación fue de corte transversal; se realizó un muestreo aleatorio simple de las diferentes áreas como emergencia, laboratorio clínico, odontología, hospitalización, quirófano, rayos $\mathrm{x}$, vestidores, entre otros, en un hospital de la 
ciudad de Cuenca. En total se recolectaron 200 muestras de diversas superficies (manijas de las puertas interruptores teclados de las computadoras, grifos de agua, instrumental, etc) de las áreas mencionadas.

Para la inclusión en este estudio se tomó en consideración las superficies que están en mayor contacto con el personal que labora en dicha institución y con los pacientes. Como criterios de exclusión superficies que no se encuentran en mayor contacto con el personal de salud $y$ pacientes.

Las muestras fueron recolectadas con un hisopo de algodón estéril humedecido con caldo soya tripticasa (CST). El procesamiento de las muestras se ejecutó en el laboratorio de Genética y Biología Molecular del Centro de Investigación, Innovación y Trasferencia de Tecnología (CIITT) de la universidad Católica de Cuenca.

\section{Procedimiento}

Las muestras fueron incubadas por 48 horas a una temperatura de $37^{\circ} \mathrm{C}$; para ser sembradas en agar manitol salado e incubarse nuevamente con las mismas condiciones. Se procedió a la identificación fenotípica mediante la selección de colonias fermentadoras de manitol a las cuales se les realizó la tinción de Gram. La identificación molecular se realizó en las cepas de cocos Gram positivos.

Para la extracción del ADN bacteriano de $S$. aureus se utilizó el método de lisis alcalina formada por SDS (dodecilsulfato sódico al 1\%) en $\mathrm{NAOH} 0,25 \mathrm{~N}$; para lo cual, con una asa bacteriológica se tomó colonias de la siembra en agar manitol salado y se suspendieron en tubos eppendorf con $1 \mathrm{ml}$ de agua destilada estéril, se homogenizó con la ayuda de un vortex, se centrifugó por $1 \mathrm{~min}$ a 3000 rpm descartando el sobrenadante, se agregó $50 \mu \mathrm{l}$ de la solución de lisis, se homogenizó nuevamente, se llevó a $100{ }^{\circ} \mathrm{C}$ por 15 minutos, se añadieron $450 \mu \mathrm{lde}$ agua libre de nucleasas, se centrifugo por 20 segundos a 3000 rpm y el ADN extraído se almacenó a $-20^{\circ} \mathrm{C}$, hasta el momento de la amplificación.

La identificación genotípica de S.aureus se realizó por medido de la reacción de la cadena de la polimerasa punto final (PCR), de los genes nucA, femB, específicos para esta bacteria, se utilizó $S$. aureus ATCC $\mathbb{B} 11632$ como control positivo y Streptococcus pyogenes ATCC $₫$ 12344 como control negativo. (Tabla 1 ).

Tabla 1. Iniciadores, de producto amplificado y condiciones de amplificación de genes писA, femB.

\begin{tabular}{|c|c|c|c|}
\hline Amplicones & $\begin{array}{l}\text { Secuencia de los primers } \\
\qquad 5^{\prime}-3^{\prime}\end{array}$ & $\begin{array}{l}\text { Condiciones para la } \\
\text { corrida de la PCR }\end{array}$ & Referencia \\
\hline $\begin{array}{l}\text { nucA } \\
270 \mathrm{pb}\end{array}$ & $\begin{array}{l}\text { Forward: 5' GCG ATT GAT GGT } \\
\text { GAT ACG GTT 3' } \\
\text { Reverse: 5' AGC CAA GCC TTG } \\
\text { ACG AAC TAA AGC 3' }\end{array}$ & $\begin{array}{l}\text { Desnaturalización inicial } \\
94^{\circ} \mathrm{C} \text { por } 5 \mathrm{~min}, 10 \text { ciclos de } \\
94^{\circ} \mathrm{C} \text { por } 40 \mathrm{~s}, 68^{\circ} \mathrm{C} \text { por } 40 \mathrm{~s} \text {, } \\
72^{\circ} \mathrm{C} \text { por } 1 \mathrm{~min} \text {, seguido de } \\
25 \text { ciclos de } 94^{\circ} \mathrm{C} \text { por } 1 \mathrm{~min} \text {, } \\
58^{\circ} \mathrm{C} \text { por } 1 \mathrm{~min}, 72^{\circ} \mathrm{C} \text { por } \\
2 \mathrm{~min} \text { y una extensión final } \\
\text { de } 10 \mathrm{~min} \text { a } 72^{\circ} \mathrm{C} \text {. }\end{array}$ & $\begin{array}{l}\text { Hamdan y et al., } \\
(24) .\end{array}$ \\
\hline
\end{tabular}




\begin{tabular}{|c|c|c|c|}
\hline Amplicones & $\begin{array}{l}\text { Secuencia de los primers } \\
\qquad 5^{\prime}-3^{\prime}\end{array}$ & $\begin{array}{l}\text { Condiciones para la } \\
\text { corrida de la PCR }\end{array}$ & Referencia \\
\hline $\begin{array}{l}\text { femB } \\
651 \mathrm{pb}\end{array}$ & $\begin{array}{l}\text { Forward: 5' TTA CAG AGT } \\
\text { TAA CTG TTA CC 3' } \\
\text { Reverse: 5' ATA CAA ATC CAG } \\
\text { CAC GCT CT 3' }\end{array}$ & $\begin{array}{l}\text { Desnaturalización inicial: } 94 \\
{ }^{\circ} \mathrm{C} \text { por } 15 \text { minutos, seguido } \\
\text { de } 35 \text { ciclos de } 94{ }^{\circ} \mathrm{C} \text { por } 45 \\
\text { segundos } 50{ }^{\circ} \mathrm{C} \text { por } 45 \\
\text { segundos y } 72{ }^{\circ} \mathrm{C} \text { por } 60 \\
\text { segundos con una extensión } \\
\text { final de } 72{ }^{\circ} \mathrm{C} \text { por } 5 \text { minutos }\end{array}$ & $\begin{array}{l}\text { Hamdan y et al., } \\
(24) .\end{array}$ \\
\hline
\end{tabular}

La separación de los productos de PCR se realizó por medio de electroforesis horizontal en $50 \mathrm{ml}$ de gel de agarosa al $1.5 \%$ con 2 ul de bromulo de etilio por 60 min en una cámara BIOSECT GELCO UNIT con TAE buffer $1 \mathrm{X}$, a $90 \mathrm{~V}$, el resultado de la electroforesis se fotografió en un transluminador de luz UV. (Figura 1).

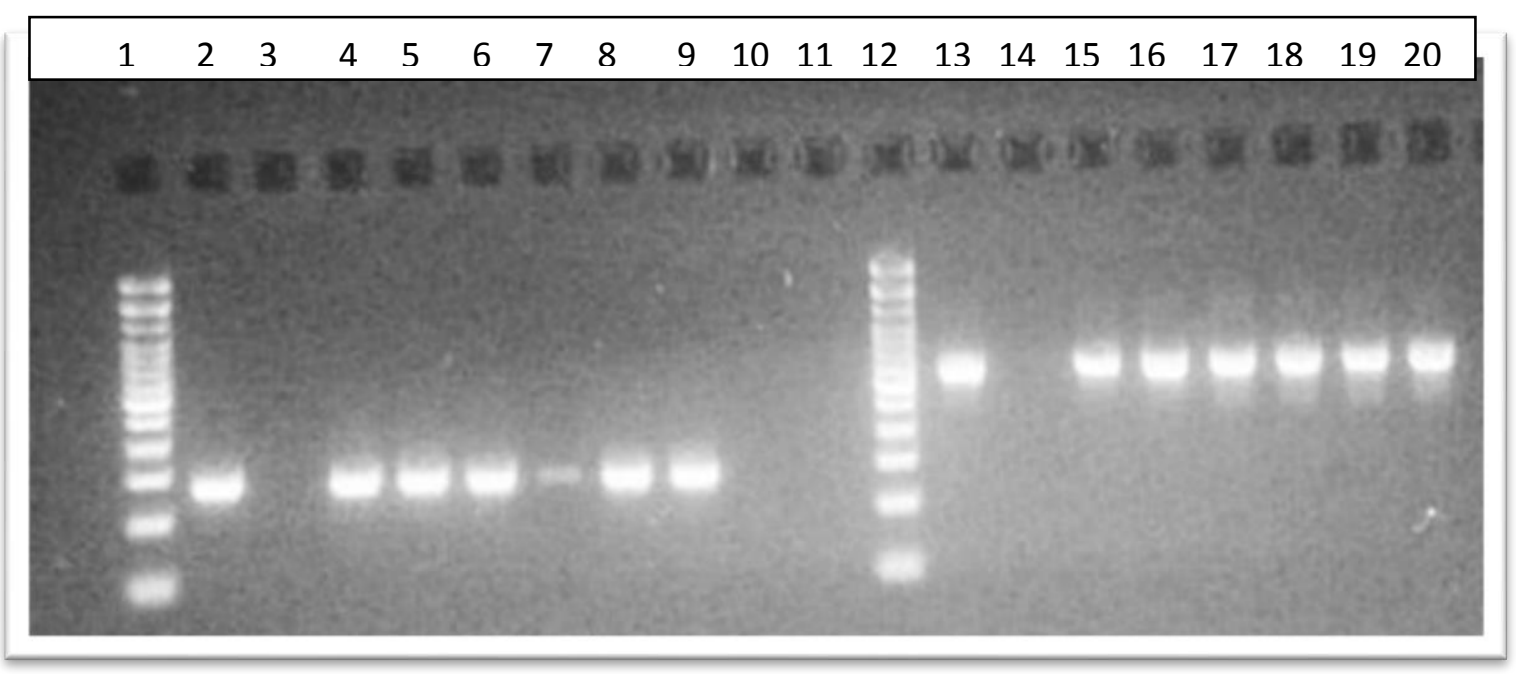

Figura 1. Productos de PCR para el gen nucA (270pb) y femB (651 pb) de S. aureus aislados de las superficies hospitalarias, carril 1: marcador de Peso Molecular (PM); carril 2 cepa control positivo; carriles 3 cepa control negativo; carriles 4, 5, 6, 7, 8,9 cepas positivas de nucA. Carril 12: ,marcador de PM, carriel 13: cepa control positivo, carril 14 cepa control negativo, carriles 15,16,17,18,19,20 cepas positivas para femB.

La valoración de la susceptibilidad de las cepas aisladas, se realizó mediante la técnica Kirby-Bauer o disco difusión en agar Mueller Hinton (Difco-EEUU). Según las recomendaciones del CLSI, para la cual se preparó una suspensión de bacterias estandarizado con el patrón de McFarland 0.5 , esta suspensión se inoculo en placas de agar Muller Hinton sobre el cual se colocaron los discos de penicilina (10ug), oxacilina (5ug), amoxicilina (10ug), gentamicina (10ug), trimetoprim sulfametoxazol (25ug), rifampicina (5ug), tetraciclina (30ug), cloranfenicol (30ug), vancomicina (30ug), linezolid (30ug )y fueron incubados a $35{ }^{\circ} \mathrm{C}$ por 24 horas, luego se realizó la lectura de los halos y se interpretó de acuerdos a los criterios del CLSI: sensible, intermedio, resistente. 
Procesamiento, análisis, resumen y presentación de la información

Para el análisis estadístico se generó una base de datos en el programa IBM SPSS Statistics, versión 25. El presente estudio se llevó a cabo mediante un análisis descriptivo relacional; para el análisis descriptivo se realizó tablas de frecuencia, posterior a esto se realizó un análisis relacional de Spearman. Para presentar los resultados se utilizó tablas simples y gráficos de barras.

\section{RESULTADOS Y DISCUSIÓN}

$\mathrm{E}$ n las 200 muestras obtenidas de la casa de salud se aisló seis cepas de $S$. aureus. Estás fueron identificadas por medio de los genes писA y femB. Las áreas donde se evidenció presencia de $S$. aureus fueron: emergencia (33.33\%), odontología, vestidores, rayos X y ecografía (16.67\%). (Ver Gráfico 1).

El proceso de identificación de S. aureus fue por medio de los genes nucA y femB.

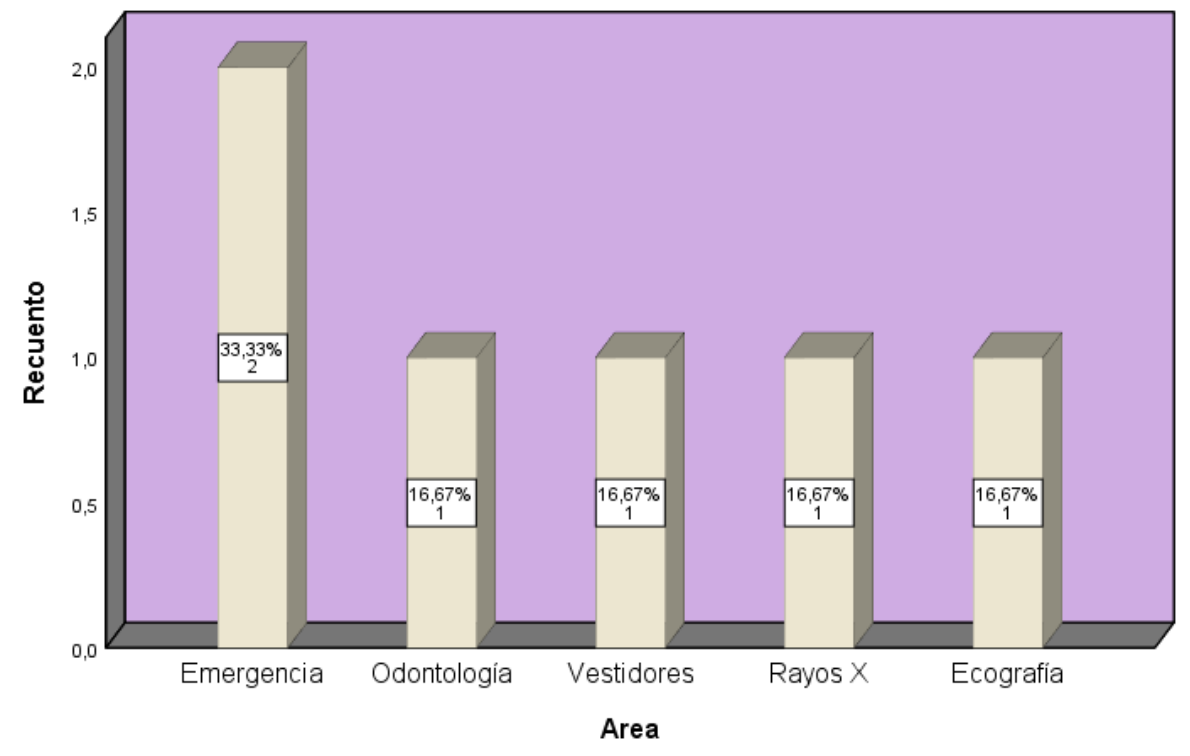

Grafico 1. Distribución de S. aureus en las superficies de las diferentes áreas del hospital.

De las seis cepas que fueron aisladas en las diferentes superficies, el 100\% presentaron resistentes a la penicilina, oxacilina y amoxicilina, con sensibilidad a trimetoprim sulfametoxazol, rifampicina, tetraciclina, cloranfenicol, vancomicina y linezolid. (Tabla 2). 
Tabla 2. Susceptibilidad a de S. aureus a los diferentes antibióticos.

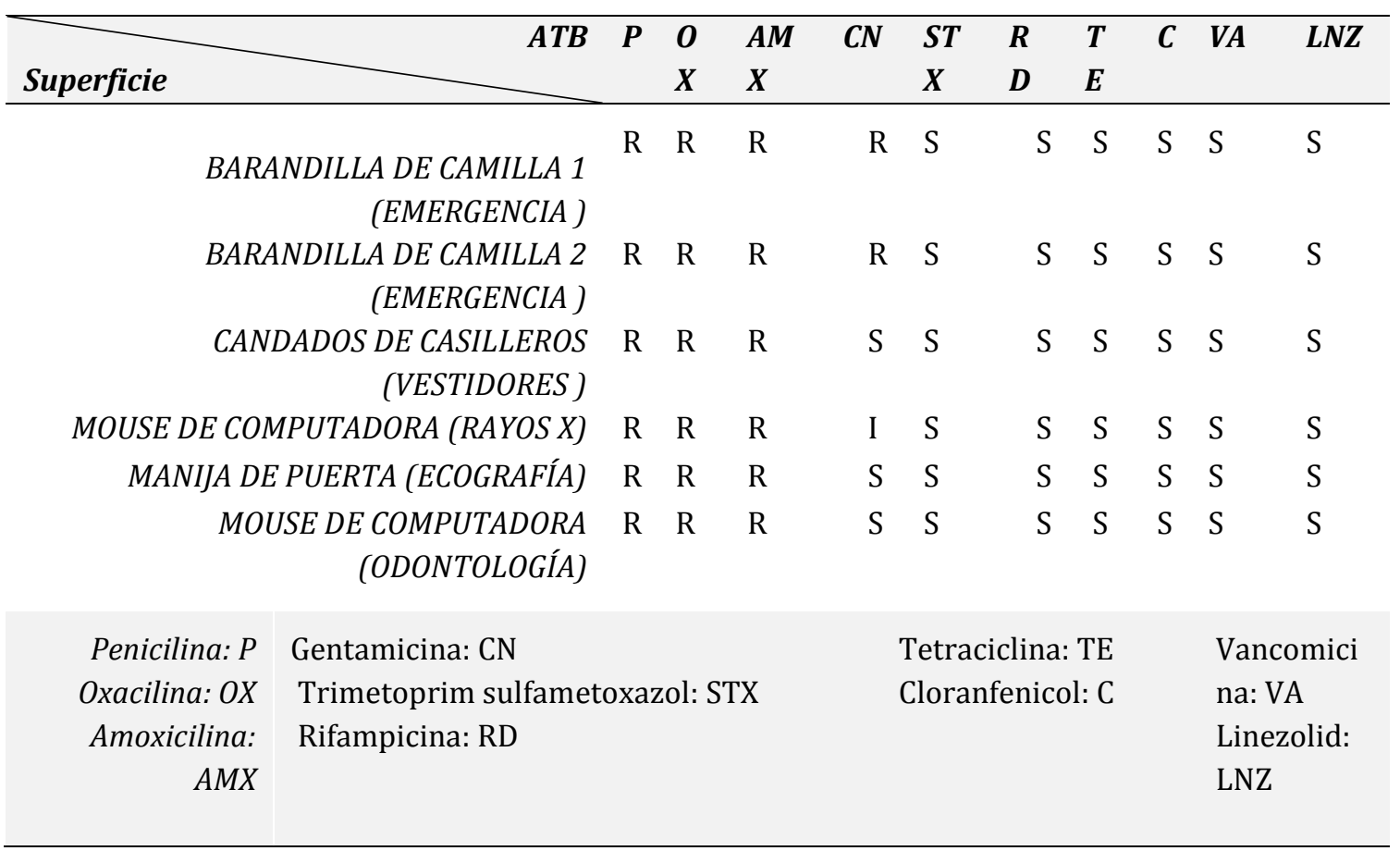

En cuanto a la gentamicina, las cepas aisladas (2) en las barandas de las camillas $33,33 \%$ situadas en el área de emergencia presentan resistencia a este antimicrobiano, por otra parte la cepa aislada (1) del mouse de computadora
(16.7\%) ubicado en el área de rayos X manifiesta una resistencia intermedia. Por último se aprecia que el $50 \%$ de las cepas (3) muestran sensibilidad hacia este medicamento (Tabla 3).

Tabla 3. Susceptibilidad a la gentamicina por S. aureus

\begin{tabular}{llllll}
\hline Gentamicina 10ug & & & & \\
\hline & Frecuencia & Porcentaje & $\begin{array}{l}\text { Porcentaje } \\
\text { válido }\end{array}$ & $\begin{array}{l}\text { Porcentaje } \\
\text { acumulado }\end{array}$ \\
& Resistente & 2 & 33,3 & 33,3 & 33,3 \\
Válido & Intermedio & 1 & 16,7 & 16,7 & 50,0 \\
& Sensible & 3 & 50,0 & 50,0 & 100,0 \\
& Total & 6 & 100,0 & 100,0 & \\
\hline
\end{tabular}


Aplicado el estadístico de Spearman para calcular la posible relación existente entre las variables estudiadas se evidencia que las muestras tiene una relación positiva alta con respecto a la gentamicina Rho $=0.802 ; \mathrm{p}=>0.055$. A pesar de presentar una relación fuerte no existen diferencias significativas. Por otra parte las superficies con respecto al antimicrobiano presenta una relación positiva fuerte además, de la presencia de diferencias significativas $\mathrm{Rho}=0.926 ; \mathrm{p}=0.008$. En cuanto a la relación entre la muestra y el área presenta una relación fuerte positiva, al igual que diferencias significativas Rho= 0.986; $\mathrm{p}=<0.05$ (Tabla 4).

Tabla 4. Relaciones entre muestra, superficies y gentamicina.

\begin{tabular}{|c|c|c|c|c|c|}
\hline & & & Superficies & Area & Gentamicina10ug \\
\hline \multirow[t]{6}{*}{$\begin{array}{l}\text { Rho de } \\
\text { Spearman }\end{array}$} & \multirow[t]{3}{*}{ Muestra } & $\begin{array}{l}\text { Coeficiente de } \\
\text { correlación }\end{array}$ & ,829* &, $986^{* *}$ & ,802 \\
\hline & & Sig. (bilateral) & ,042 & 000, & 055, \\
\hline & & $\mathrm{N}$ & 6 & 6 & 6 \\
\hline & \multirow[t]{3}{*}{ Superficies } & $\begin{array}{l}\text { Coeficiente de } \\
\text { correlación }\end{array}$ & 1,000 & ,812* &, $926^{* *}$ \\
\hline & & Sig. (bilateral) & . & 050, & 008, \\
\hline & & $\mathrm{N}$ & 6 & 6 & 6 \\
\hline $\begin{array}{l}* \text { *. La correl } \\
* * \text {. La corre }\end{array}$ & $\begin{array}{l}\text { ión es signif } \\
\text { ción es sign }\end{array}$ & $\begin{array}{l}\text { iva en el nivel } \\
\text { tiva en el nive }\end{array}$ & $\begin{array}{l}\text { (bilateral). } \\
\text { (bilateral) }\end{array}$ & & \\
\hline
\end{tabular}

\section{Discusión}

En Ecuador según el reporte del Instituto Nacional de Investigación en Salud Publica la frecuencia de aislamiento es un $12 \%$ para $S$. aureus; dentro de los antibióticos con mayor porcentaje de resistencia es la penicilina seguido por la eritromicina desde el 2014 al 2017 en aislados de los servicios hospitalarios (25).

En este estudio se demuestra la presencia de $S$. aureus en algunas superficies de esta casa de salud, lo cual demuestra la facilidad que tiene esta bacteria de sobrevivir en diferentes superficies (26).

Comparando los resultados obtenidos en este estudio con los de Cabrera (27) realizada en Cali- Colombia en aislados de cepas $S$. aureus de diversas superficies hospitalarias, en el cual se encontró un porcentaje mayor de cepas aisladas de esta bacteria con resistencia a penicilina $\mathrm{y}$ oxacilina en menor porcentaje a los resultados de este estudio, a diferencia de la resistencia del $30 \%$ presentada a la tetraciclina; en este estudio las cepas aisladas de la superficies son sensibles.

Por otro lado, Chávez et al., (22) de la misma ciudad de Cali detectó el $12.2 \%$ de aislados de $S$. aureus de 167 muestras obtenidas en ambientes hospitalarios, con una resistencia simultánea a gentamicina, tetraciclina, clorafenicol y oxacilina de $20 \%$, dichos resultado discrepan con los de esta investigación al haber resistencia al $100 \%$ a oxacilina, gentamicina $33.3 \%$ y sensibilidad a tetraciclina y clorafenicol. 
Otros autores también reportan porcentajes superiores de esta bacteria en aislados hospitalarios en comparación a los de este estudio, así como en la investigación realizada por Rivera et al., (28) obtuvieron 17 cepas de $S$. aureus en ambientes de cirugía y obstetricia, Mukhiya et al., (29). reportan una prevalencia en el entorno hospitalario de $14.3 \%$ de $S$, aureus con $45.9 \%$ de resistencia a la meticilina; por otro lado en un hospital en Nigeria reporta una contaminación por este microbio con $54 \%$ (30).

En contraste con los resultados de este estudio Glowacki et al., (31) aislaron $S$. aureus $12 \%$ en superficies inanimadas de la área de emergencia con sensibilidad a penicilina y oxacilina, de igual manera Prince et al., (32) determinaron la trasmisión de esta bacteria entre el personal de salud, pacientes, el medio ambiente en una UCI obteniendo $12.95 \%$ de resistencia a la meticilina en las cepas aisladas de $S$. aureus, otro estudio en Venezuela reporta $15 \%$ de este microorganismo aislado en las superficies del quirófano de un hospital resultado contrarios al de este estudio ya que no existió crecimiento en las superficies de esta área (33).

Un estudio realizado en Libia demostró la resistencia de $S$. aureus aislado de un ambiente hospitalario a diferentes antibióticos similares al de este estudio como a penicilina y oxacilina al $100 \%$; la resistencia a la gentamicina $25 \%$ es menor a comparación al de este estudio y susceptibilidad a la vancomicina, rifampicina en su totalidad (34).

Por otro lado, se evidencia la habilidad de $S$. aureus de colonizar diferentes superficies como en barandas de camas en un $37.5 \%$ evidenciado por Ferreira et al.,
(21) porcentaje casi igual a este estudio, en otro estudio en el cual se midió la contaminación por MRSA en salas de un hospital en 2014 se encontró patrones de contaminación menor al de este estudio en barandas de camillas, sin embargo un porcentaje similar de MRSA al presente estudio en los colchones (35).

De la misma manera se demostró la presencia de $S$. aureus en un $3 \%$ en las manijas de puertas en un hospital de Ghana con un patrón de resistencia total a penicilina lo cual concuerda con los resultados de este estudio, dichas cepas aisladas también presentaron resistencia a tetraciclina y a trimetoprim sulfametoxazo. (36).

\section{CONCLUSIÓN}

$\mathrm{E}$ bajo porcentaje de aislados de $S$. aureus en este estudio puede deberse a que esta investigación se realizó en un hospital básico, y la estancia hospitalaria es baja lo cual disminuye las posibilidades de trasmisión de patógenos entre los pacientes y el personal de salud, no obstante es importante mantener la normas de desinfección para evitar que las áreas de este hospital se conviertan en reservorios para $S$. aureus y de otros microorganismo patógenos.

En base a los resultados obtenidos la mayoría de los aislados de $S$. aureus son resistentes a las penicilinas empleadas en este estudio, por lo que es recomendable mantener medidas de vigilancia epidemiológica de la resistencia presentadas por las cepas aisladas en las diferentes superficies, con el objetivo de controlar la diseminación de cepas multirresitentes principalmente SARM, que es uno de los patógenos con importancia entre los procesos infecciosos lo cual puede alargar el 
tiempo de estancia hospitalaria, generar altos costos para el sistema de salud y comprometer la vida de los pacientes.

Se recomienda que para próximos estudios realizar pruebas moleculares para genes de resistencia como blaZ y MecA.

\section{REFERENCIAS BIBLIOGRÁFICAS}

1. Diana L, Ciuffo C, Musto H, Diana L, Ciuffo C, Musto H. Identificación y caracterización de Staphylococcus resistentes a meticilina aislados de perros. Veterinaria (Montevideo) [Internet]. 2019 [citado 12 de diciembre de 2020];55(212):45-51. Disponible en: http://www.scielo.edu.uy/scielo.php?scrip $\mathrm{t}=$ sci_abstract\&pid=S1688-

48092019000200045\&lng=es\&nrm=iso\&t lng=es

2. Portillo ME, del Pozo JL. Infecciones por estafilococo. Medicine - Programa de Formación Médica Continuada Acreditado [Internet]. 2018 [citado 12 de diciembre de 2020];12(49):2890-4. Disponible en: http://www.sciencedirect.com/science/ar ticle/pii/S0304541218300210

3. Vega MD la, Vergiu CC. Presencia de Staphylococcus aureus después del lavado de \{manos quirúrgico en estudiantes de odontología. Revista KIRU [Internet]. 2019 [citado 9 de diciembre de 2020];16(2). Disponible en: https://www.aulavirtualusmp.pe/ojs/inde x.php/Rev-Kiru0/article/view/1556

4. Togneri AM, Podestá LB, Pérez MP, Santiso GM. Estudio de las infecciones por Staphylococcus aureus en un hospital general de agudos (2002-2013). Rev Argent Microbiol [Internet]. 2017 [citado 12 de diciembre de 2020];49(1):24-31. Disponible en: http://www.sciencedirect.com/science/ar ticle/pii/S032575411630092X

5. Founou RC, Founou LL, Essack SY. Extended spectrum beta-lactamase mediated resistance in carriage and clinical gram-negative ESKAPE bacteria: a comparative study between a district and tertiary hospital in South Africa. Antimicrob Resist Infect Control [Internet]. 2018 [citado 12 de diciembre de 2020];7(1):134. Disponible en: https://doi.org/10.1186/s13756-0180423-0

6. Andrade C, Orellana P. Frecuencia y susceptibilidad a penicilina y meticilina de aislamientos ambientales de Staphylococcus aureus en un hospital de Cuenca. Kasmera [Internet]. 2019 [citado 10 de diciembre de 2020];47(2):123-30. Disponible en: https://produccioncientificaluz.org/index. $\mathrm{php} /$ kasmera/article/view/27470

7. Sierra Benítez EM, León Pérez MQ, Sierra Benítez EM, León Pérez MQ. Terapia antibacteriana: origen y evolución en el tiempo. Rev Med Electrón [Internet]. 2019 [citado 17 de diciembre de 2020];41(5):1300-8. Disponible en: http://scielo.sld.cu/scielo.php?script=sci_a bstract\&pid=S1684-

$18242019000501300 \& \operatorname{lng}=\mathrm{es} \& \mathrm{nrm}=\mathrm{iso} \& \mathrm{t}$ lng=es

8. García A, Martínez C, Juárez RI, Téllez $\mathrm{R}$, Paredes MA, Herrera $M$ del $\mathrm{R}$, et al. Methicillin resistance and biofilm production in clinical isolates of Staphylococcus aureus and coagulasenegative Staphylococcus in México. Biomédica [Internet]. 2019 [citado 13 de diciembre de 2020];39(3):513-23. Disponible en: http://www.scielo.org.co/scielo.php?scrip $\mathrm{t}=$ sci_abstract\&pid=S0120-

$41572019000300513 \& \operatorname{lng}=e n \& n r m=i s o \& t$ lng=es

9. Lee AS, de Lencastre H, Garau J, Kluytmans J, Malhotra-Kumar S, Peschel A, et al. Methicillin-resistant Staphylococcus aureus. Nat Rev Dis Primers [Internet]. 2018 [citado 6 de diciembre de 2020];4(1):1-23. Disponible en: https://www.nature.com/articles/nrdp20 1833

10. Aguayo-Reyes A, Quezada-Aguiluz $M$, Mella S, Riedel G, Opazo-Capurro A, BelloToledo $\mathrm{H}$, et al. Bases moleculares de la resistencia a meticilina en Staphylococcus 
aureus. Rev chil infectol [Internet]. 2018 [citado 13 de diciembre de 2020];35(1):7$14 . \quad$ Disponible en: https://scielo.conicyt.cl/scielo.php?script= sci_abstract\&pid=S0716-

10182018000100007\&lng=es\&nrm=iso\&t lng=e

11. Chávez-Jacobo VM. La batalla contra las superbacterias: No más antimicrobianos, no hay ESKAPE. TIP RECQB [Internet]. 2020 [citado 15 de diciembre de 2020];23. Disponible en: http://tip.zaragoza.unam.mx/index.php/ti p/article/view/202

12. Labarca J. Hetero-resistencia en Staphylococcus aureus con resistencia intermedia a vancomicina, ¿susceptible o resistente? Rev chil infectol [Internet]. octubre de 2015 [citado 14 de diciembre de 2020];32(5):497-8. Disponible en: https://scielo.conicyt.cl/scielo.php?script= sci_abstract\&pid=S0716-

$10182015000600001 \& \operatorname{lng}=e s \& n r m=i s o \& t$ lng=es

13. López IB, Ballesté MG, González AC, Morán RA, Hernández BP, Valdés YND. Resistencia de Staphylococcus aureus frente a cefalosporinas en la sepsis neonatal y puerperal. Revista Cubana de Obstetricia y Ginecología [Internet]. 2019 [citado 13 de diciembre de 2020];45(1):1$13 . \quad$ Disponible en: https://www.medigraphic.com/cgibin/new/resumen.cgi?IDARTICULO=9141 5

14. Caicedo-Ochoa EY, Urrutia-Gómez JA, Fernández-Niño DS, Guío-Guerra SA, Méndez-Fandiño YR. Tratamiento de la bacteriemia por enterococo resistente a vancomicina con daptomicina versus linezolid: revisión sistemática y metanálisis. Iatreia [Internet]. 2017 [citado 15 de diciembre de 2020];30(1):5-20. Disponible en: http://www.scielo.org.co/scielo.php?scrip $\mathrm{t}=$ sci_abstract\&pid=S0121-

07932017000100005\&lng=en\&nrm=iso\&t lng=es

15. Carmona-Torre F, del Pozo JL. Tratamiento de las infecciones por
Staphylococcus aureus. Medicine Programa de Formación Médica Continuada Acreditado [Internet]. 1 de febrero de 2018 [citado 15 de diciembre de 2020];12(49):2918-23. Disponible en: http://www.sciencedirect.com/science/ar ticle/pii/S030454121830026X

16. Gharsa H, Dziri R, Klibi N, Chairat $S$, Lozano C, Torres C, et al. Environmental Staphylococcus aureus contamination in a Tunisian hospital. Journal of Chemotherapy [Internet]. 1 de noviembre de 2016 [citado 13 de diciembre de 2020];28(6):506-9. Disponible en: https://doi.org/10.1179/1973947815Y.00 00000036

17. Hernández-Orozco HG, CastañedaNarváez JL, Garza EA la. Celulares y riesgo de infecciones intrahospitalarias. Rev Latin Infect Pediatr [Internet]. octubre de 2017 [citado 10 de diciembre de 2020];30(2):45-7. Disponible en: https://www.medigraphic.com/cgibin/new/resumen.cgi?IDARTICULO=7466 2

18. Llanos-Torres KH, Pérez-Orozco R, Málaga G. Infecciones nosocomiales en unidades de observación de emergencia y su asociación con el hacinamiento y la ventilación. Rev Peru Med Exp Salud Publica [Internet]. 3 de febrero de 2021 [citado 9 de marzo de 2021];37:721-5. Disponible en: https://www.scielosp.org/article/rpmesp /2020.v37n4/721-725/es/

19. Verea LP, Ferrer AF, Reyes YO, Miranda YP, Méndez AR. Infecciones nosocomiales y resistencia antimicrobiana. Rev Cub Med Int Emerg [Internet]. 2019 [citado 9 de marzo de 2021];18(1):1-17. Disponible en: https://www.medigraphic.com/cgibin/new/resumen.cgi?IDARTICULO=8732 6

20. Flores Cabeza E, Sánchez Sánchez $M$, Añón Elizalde JM, Gutiérrez Melón C. Infecciones relacionadas con la asistencia sanitaria (nosocomiales). Medicine Programa de Formación Médica Continuada Acreditado [Internet]. 1 de 
abril de 2018 [citado 9 de marzo de 2021];12(52):3076-84. Disponible en: https://www.sciencedirect.com/science/a rticle/pii/S0304541218300635

21. Ferreira AM, Andrade D de, Rigotti MA, Almeida MTG de, Guerra OG, Santos AG dos. Evaluación de la desinfección de superficies hospitalarias por diferentes métodos de monitorización1. Rev LatinoAm Enfermagem [Internet]. junio de 2015 [citado 3 de junio de 2021];23:466-74. Disponible

en: https://www.scielo.br/j/rlae/a/zTbWrRD 36PksLqLWVytnPWh/?lang=es

22. Chávez-Vivas $M$, Martínez $A$ del $C$, Esparza-Mantilla $M$, Chávez-Vivas $M$, Martínez A del C, Esparza-Mantilla M. CARACTERIZACIÓN DE Staphylococcus aureus OBTENIDO DEL AMBIENTE HOSPITALARIO Y DEL PERSONAL DE SALUD EN UN HOSPITAL DE LA CIUDAD DE CALI. Biosalud [Internet]. diciembre de 2017 [citado 8 de mayo de 2021];16(2):22-33. Disponible en: http://www.scielo.org.co/scielo.php?scrip $\mathrm{t}=$ sci_abstract\&pid=S1657-

95502017000200022\&lng=en\&nrm=iso\&t lng=es

23. Andrade T C, Orellana B P. Frecuencia y susceptibilidad a penicilina y meticilina de aislamientos ambientales de Staphylococcus aureus en un hospital de Cuenca. 1 de diciembre de 2019 [citado 3 de junio de 2021]; Disponible en: https://zenodo.org/record/3406805

24. Hamdan A, González-García S, Bustos Martinez J. Identificación de Staphylococcus aureus utilizando como marcadores los genes nucA y femB. Ciencias Clínicas. 1 de marzo de 2016;16.

25. gaceta_ram2018.pdf [Internet]. [citado 6 de julio de 2021]. Disponible en: https://www.salud.gob.ec/wp-

content/uploads/2019/08/gaceta_ram201 8.pdf

26. Hernández-Orozco HG, CastañedaNarváez JL. Celulares y riesgo de infecciones intrahospitalarias. Revi Latino de InfeC Ped [Internet]. 30:3. Disponible en: https://www.medigraphic.com/pdfs/infec tologia/lip-2017/lip172a.pdf

27. Cabrera Tello $M$, Chávez Vivas $M$. Patógenos de importancia clínica Caracterización fenotípica y molecular de Staphylococcus aureus aislado de superficies del ambiente hospitalario de la red pública y privada en la ciudad de Cali. En Universidad Santiago de cali; 2018 [citado 8 de mayo de 2021]. Disponible en: https://repository.usc.edu.co/handle/20.5 $00.12421 / 932$

28. Rivera-Jacinto $M$, Rodríguez-Ulloa $C$, Huayán-Dávila G. Frecuencia de aislamientos ambientales de Staphylococcus aureus y su actividad betalactamasa en un hospital de Cajamarca, Perú. Infectio [Internet]. 1 de septiembre de 2009 [citado 14 de junio de 2021];13(3):192-5. Disponible en: https://www.sciencedirect.com/science/a rticle/pii/S0123939209701493

29. Mukhiya RK, Shrestha A, Rai SK, Panta K, Singh RN, Rai G, et al. Prevalence of Methicillin-Resistant Staphylococcus aureus in Hospitals of Kathmandu Valley. Nepal Journal of Science and Technology [Internet]. 2012 [citado 14 de junio de 2021];13(2):185-90. Disponible en: https://www.nepjol.info/index.php/NJST/ article/view/7734

30. Odoya M, Ohenhen R, Adias T, Stanley 0 , Ojusin G. An Overview of the Distribution of Staphylococcus aureus in the hospital Environment. 1 de julio de 2015;9:31-3.

31. Glowacki CM, Sales WB, PereiraMaciel RA, Vasco JF de M. IDENTIFICAÇÃO DE MICRORGANISMOS ISOLADOS DE SUPERFÍCIES INANIMADAS DE CONTATO DE UMA UNIDADE DE PRONTO ATENDIMENTO. Anais do EVINCI UniBrasil [Internet]. 2015 [citado 20 de junio de 2021];1(4):152-61. Disponible en:

https://portaldeperiodicos.unibrasil.com.b r/index.php/anaisevinci/article/view/863 32. Price JR, Cole K, Bexley A, Kostiou V, Eyre DW, Golubchik T, et al. Transmission 
of Staphylococcus aureus between healthcare workers, the environment, and patients in an intensive care unit: a longitudinal cohort study based on wholegenome sequencing. The Lancet Infectious Diseases [Internet]. 1 de febrero de 2017 [citado 20 de junio de 2021];17(2):207$14 . \quad$ Disponible en: https://www.sciencedirect.com/science/a rticle/pii/S1473309916304133

33. Izzeddin N, Rodríguez GA, Medina L, González L. Evaluación microbiológica de aire y superficies en quirófano de un centro de salud público. Salus. 2017;21(3):18-23.

34. Al-Abdli NE, Baiu SH, Al-Abdli NE, Baiu SH. Isolation of MRSA Strains from Hospital Environment in Benghazi City, Libya [Internet]. Vol. 4. 2016; Disponible en: $10.12691 /$ ajidm-4-2-4.

35. Creamer E, Shore AC, Deasy EC, Galvin S, Dolan A, Walley N, et al. Air and surface contamination patterns of meticillinresistant Staphylococcus aureus on eight acute hospital wards. Journal of Hospital Infection [Internet]. 1 de marzo de 2014 [citado 26 de junio de 2021];86(3):201-8. Disponible en: https://www.sciencedirect.com/science/a rticle/pii/S0195670114000048

36. Tagoe DN, Desbordes KK. Investigating potential sources of transmission of healthcare-associated infections in a regional hospital, Ghana. International Journal of Applied and Basic Medical Research [Internet]. 1 de enero de 2012 [citado 15 de junio de 2021];2(1):20. Disponible en: https://www.ijabmr.org/article.asp?issn= 2229-

516X;year $=2012$; volume $=2$;issue $=1$; spage $=20$; epage $=24 ;$ aulast $=$ Tagoe ;ype $=0$

Conflicto de Intereses: Los autores declaran no presentar conflictos de intereses.

Financiación: Por los autores.

Agradecimiento: Ninguno manifestado por los autores 